Trinity University

Digital Commons@ Trinity

Chemistry Faculty Research

Chemistry Department

5-18-2011

\title{
Determining Protease Substrate Selectivity and Inhibition by Label-Free Supramolecular Tandem Enzyme Assays
}

Garima Ghale

Vijayakumar Ramalingam

Trinity University, vramalin@trinity.edu

Adam R. Urbach

TrinityUniversity, aurbach@trinity.edu

Werner M. Nau

Follow this and additional works at: https://digitalcommons.trinity.edu/chem_faculty

Part of the Chemistry Commons

\section{Repository Citation}

Ghale, G., Ramalingam, V., Urbach, A. R., \& Nau, W. M. (2011). Determining protease substrate selectivity and inhibition by labelfree supramolecular tandem enzyme assays. Journal of the American Chemical Society, 133(19), 7528-7535. doi: 10.1021/ja2013467

This Post-Print is brought to you for free and open access by the Chemistry Department at Digital Commons @ Trinity. It has been accepted for inclusion in Chemistry Faculty Research by an authorized administrator of Digital Commons @ Trinity. For more information, please contact jcostanz@trinity.edu. 


\title{
Determining Protease Substrate Selectivity and Inhibition by Label-free Supramolecular Tandem Enzyme Assays
}

\author{
Garima Ghale, ${ }^{\S}$ Vijayakumar Ramalingam, ${ }^{\dagger}$ Adam R. Urbach, ${ }^{\dagger} *$ and Werner M. Nau ${ }^{\S, *}$
}

\author{
$\S$ School of Engineering and Science, Jacobs University Bremen, Campus Ring 1, D-28759 \\ Bremen, Germany, E-mail: w.nau@jacobs-university.de \\ ${ }^{\dagger}$ Department of Chemistry, Trinity University, San Antonio, Texas 78218, U.S.A., \\ E-mail: aurbach@trinity.edu
}

\begin{abstract}
An analytical method has been developed for the continuous monitoring of protease activity on unlabelled peptides in real time by fluorescence spectroscopy. The assay is enabled by a reporter pair comprising the macrocycle cucurbit[7]uril (CB7) and the fluorescent dye acridine orange (AO). CB7 functions by selectively recognizing $\mathrm{N}$-terminal phenylalanine residues as they are produced during the enzymatic cleavage of enkephalintype peptides by the metalloendopeptidase thermolysin. The substrate peptides (e.g., ThrGly-Ala-Phe-Met- $\mathrm{NH}_{2}$ ) bind to $\mathrm{CB} 7$ with moderately high affinity $\left(K\right.$ ca. $\left.10^{4} \mathrm{M}^{-1}\right)$, while their cleavage products (e.g., Phe-Met- $\left.\mathrm{NH}_{2}\right)$ bind very tightly $\left(K>10^{6} \mathrm{M}^{-1}\right)$. AO signals the reaction upon its selective displacement from the macrocycle by the high affinity product of proteolysis. The resulting supramolecular tandem enzyme assay effectively measures the kinetics of thermolysin, including the accurate determination of sequence specificity (Ser and Gly instead of Ala), stereospecificity (DAla instead of LAla), endo- versus exopeptidase activity (indicated by differences in absolute fluorescence response), and sensitivity to terminal charges $\left(-\mathrm{CONH}_{2}\right.$ versus $\left.-\mathrm{COOH}\right)$. The capability of the tandem assay to measure protease inhibition constants was demonstrated on phosphoramidon as a known inhibitor to afford an inhibition constant of $(17.8 \pm 0.4) \mathrm{nM}$. This robust and label-free approach to the study of protease activity and inhibition should be transferable to other endo- and exopeptidases that afford products with $\mathrm{N}$-terminal aromatic amino acids.
\end{abstract}




\section{Introduction}

As the enzymes that catalyze the hydrolytic degradation of proteins, proteases are ubiquitous in living systems and regulate a multitude of cellular processes including the cell cycle, hormone activation, angiogenesis, and apoptosis. ${ }^{1-5}$ Aberrations in protease expression or function are therefore implicated in many pathological conditions such as cancer, ${ }^{6}$ arthritis, ${ }^{7}$ and Alzheimer's disease. ${ }^{8}$ In addition, proteases play an essential role in viral replication and in the toxicity of bacteria. ${ }^{9}$ Indeed, the potential of proteases as targets for drug development is enormous, as evidenced by the successful development of numerous therapeutics based on protease inhibition. $^{5}$

The characterization of protease activity for the purpose of determining substrate activity and inhibitor potency is unfortunately slow and expensive. The vast majority of assays require labeled substrates, ${ }^{10-17}$ which are costly and may not behave the same as their natural counterparts. ${ }^{18}$ Label-free protease assays, on the other hand, rely on analytical instruments such as mass spectrometry, ${ }^{18}$ or employ synthetic/semi-synthetic multifunctional pores, ${ }^{19,20}$ which are difficult to scale up for high-throughput screening. Hence, the development of rapid and robust assays for protease activity greatly accelerates the characterization of protease targets and the discovery of drug candidates. ${ }^{17,21}$

This paper describes a robust and convenient approach for measuring protease kinetics using optical spectroscopy on label-free substrates and products. Our approach is based on a supramolecular tandem assay, ${ }^{22-25}$ which incorporates an essential component of indicatordisplacement assays. ${ }^{26-28}$ Supramolecular tandem assay is a recently developed technique that provides real-time continuous monitoring of enzymatic activity by following a change in the concentration of substrate or product as it competitively displaces a fluorescent reporter dye from the cavity of a macrocyclic host. These assays therefore rely on the differential binding of the macrocycle with the fluorescent dye, the enzymatic substrate, and the corresponding product.

Supramolecular tandem assays have been implemented successfully for monitoring enzymatic transformations involving amino acids, biogenic amines, amino aldehydes, and nucleotide phosphates. ${ }^{22-25}$ Until now, the technique was limited to substrates and products which, owing to their low molecular weight, could essentially be fully immersed in the macrocyclic host cavity, such that the entire analyte, e.g. arginine or cadaverine, served as 
recognition motif. Here, the utility of the tandem assay principle is transferred to peptides, which themselves are far too large to be fully included in the macrocyclic cavity. Rather, it is a residue of the peptide chain, namely an aryl ring, which complexes with differential affinity to the macrocycle in the substrate and the product. For the first time, we demonstrate the quantitative determination of absolute kinetic parameters $\left(k_{\mathrm{cat}} / K_{\mathrm{M}}\right)$ for protease activity, the application of this analysis to the profiling of enzyme substrates for sequence-selectivity, stereospecificity, and endo- vs exopeptidase activity, as well as the quantitative determination of inhibitory constants for protease inhibitors.
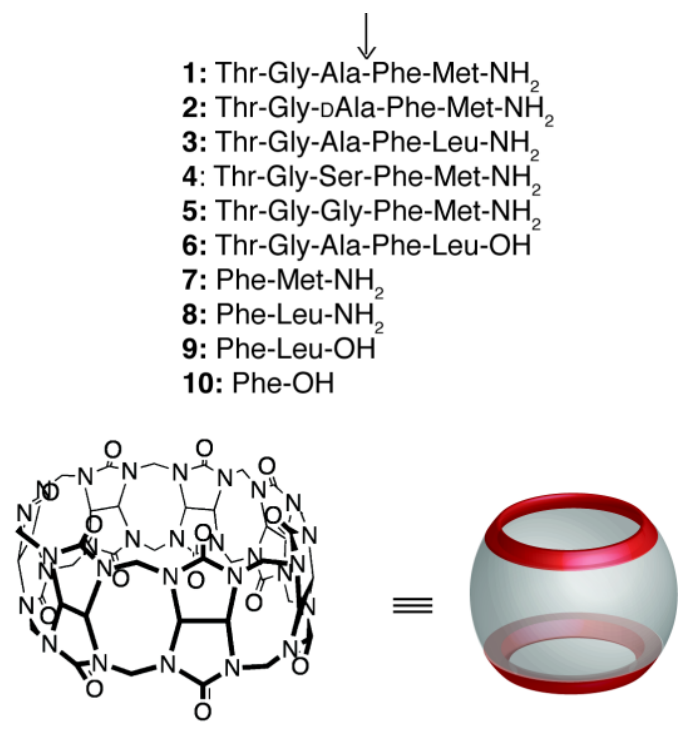

Cucurbit[7]uril (CB7)

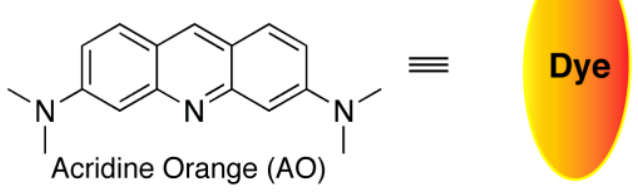

Figure 1. Amino acid sequences of the peptides used in this study; the $\mathrm{N}$ termini are unprotected primary amines, the $\mathrm{C}$ termini are designated as $-\mathrm{NH}_{2}$ for a primary amide and $\mathrm{OH}$ for a carboxylic acid. The arrow indicates the cleavage site for thermolysin. Also shown are the chemical structures of the macrocycle and fluorescent dye constituting the employed reporter pair. 


\section{Results and Discussion}

Experimental Design. Cucurbit[7]uril (CB7, Figure 1) is a water-soluble macrocycle that has been investigated extensively in biological applications including drug delivery, ${ }^{29-33}$ interactions with enzymes, ${ }^{34,35}$ plasma membrane protein fishing, ${ }^{36}$ and label-free enzyme assays. $^{22-25}$ The repeating glycoluril units produce a barrel-shaped container that has a hydrophobic cavity and negatively charged portals. ${ }^{37}$ The latter are capable, not only for CB7 but also for its homologues, of binding inorganic cations as well as the cationic sites of organic guests, mostly ammonium groups; nonpolar groups are preferentially immersed in the inner cavity. ${ }^{38-42}$ CB7 and its larger homologue CB8 have been shown to bind aromatic amino acids and sequence-specifically to peptides and proteins containing phenylalanine (Phe), tryptophan (Trp), or tyrosine (Tyr) at the N-terminal positions. ${ }^{43-47}$ Recognition at the $\mathrm{N}$ terminus is achieved via the cooperation of hydrophobic inclusion of the aromatic side chain and electrostatic stabilization of the proximal N-terminal ammonium group.

The differential binding of $\mathrm{CB} 7$ to an aromatic residue located at the $\mathrm{N}$ terminus versus other positions is exploited here in the design of an enzyme assay by choosing a protease (thermolysin) that efficiently hydrolyzes the peptide bond on the amino side of phenylalanine residues and thus generates an N-terminal phenylalanine as its product. The product binds to CB7 more tightly than the starting material, and will, therefore, selectively displace a fluorescent indicator from CB7. This allows real-time monitoring of the thermolysinmediated reaction by the pronounced change in fluorescence intensity. Thermolysin is a thermally resistant (thermophilic) enzyme produced by Bacillus thermoproteolyticus. It is selective for bulky, hydrophobic amino acids such as Phe and Leu, ${ }^{48}$ and represents the family of thermolysin metalloendopeptidases as relevant therapeutic targets due to their high substrate specificity, their functional role in extracellular transformations of neuroendocrine as well as cardiovascular peptides, and in processes ranging from reproduction to cardiovascular homeostasis. ${ }^{9,49,50}$

Enkephalin-based peptides were chosen as substrates to establish proof-of-principle for the protease assay. These neurological pentapeptides of sequence Tyr-Gly-Gly-Phe-Met-OH (natural amino and carboxy termini) or Tyr-Gly-Gly-Phe-Leu-OH are part of the endogenous opioid system involved in pain perception and emotional behavior, and they are implicated in the pathogenesis of Alzheimer's dementia. ${ }^{51}$ Thermolysin hydrolyzes these peptides at the 
Gly-Phe peptide bond, producing Phe-Met-OH and Phe-Leu-OH products that contain an Nterminal Phe and, thus, should bind to CB7 selectively versus the substrates as well as the other peptide product fragments (Scheme 1)..$^{52-54}$

Scheme 1. CB7 binds selectively to N-terminal Phe residues due to cooperative hydrophobic and ion-dipole interactions

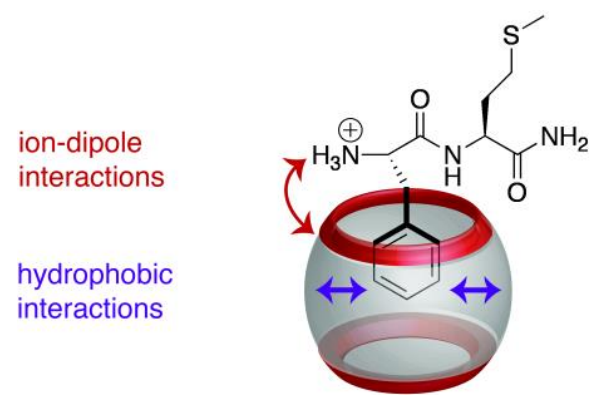

The choice of the fluorescent dye is critical to the design of a supramolecular tandem assay. Acridine orange (AO, Figure 1) and CB7 were selected as the "reporter pair" (i.e., the macrocycle and dye pair). $\mathrm{AO}$ is a weakly fluorescent dye in aqueous solution, which becomes strongly fluorescent upon encapsulation by CB7. ${ }^{55}$ Upon the addition (or enzymatic formation) of a strongly binding analyte to the preformed $\mathrm{CB} 7 \bullet \mathrm{AO}$ complex, the fluorescence intensity drops again, leading to a "switch-off" fluorescence response. Important to note, the binding constant of CB7 with AO $\left(2.9 \times 10^{5} \mathrm{M}^{-1}\right)^{24,55}$ lies in between the binding strength of CB7 with the substrate and product of interest. This was demonstrated by simple titration experiments (Figure 2 and Supporting Information), from which the binding constants of peptides 1-9 were determined (Table 1). Peptides 1-6, the candidates to potentially act as substrates for thermolysin, have invariably a low binding affinity to $\mathrm{CB} 7$, accounted by the presence of only hydrophobic interaction between the amino acid Phe and the host cavity. However, the corresponding proteolytic products (dipeptides 7-9) have 3 orders of magnitude higher affinity for $\mathrm{CB} 7$ due to the additional electrostatic interaction between the $\mathrm{N}$-terminal ammonium group of Phe with the CB7 carbonyls. This high affinity disappears again for the simple amino acid Phe (10), for which the adjacent C-terminal carboxylate group entirely offsets the stabilizing interaction by the ammonium group. Note that the binding affinity of CB7 between the peptides $\mathbf{1}$ and $\mathbf{2}$ is slightly different. Nevertheless, it is not surprising due to the diastereomeric differentiation between $\mathrm{L}$ and D Ala by an achiral host CB7. ${ }^{56}$ 


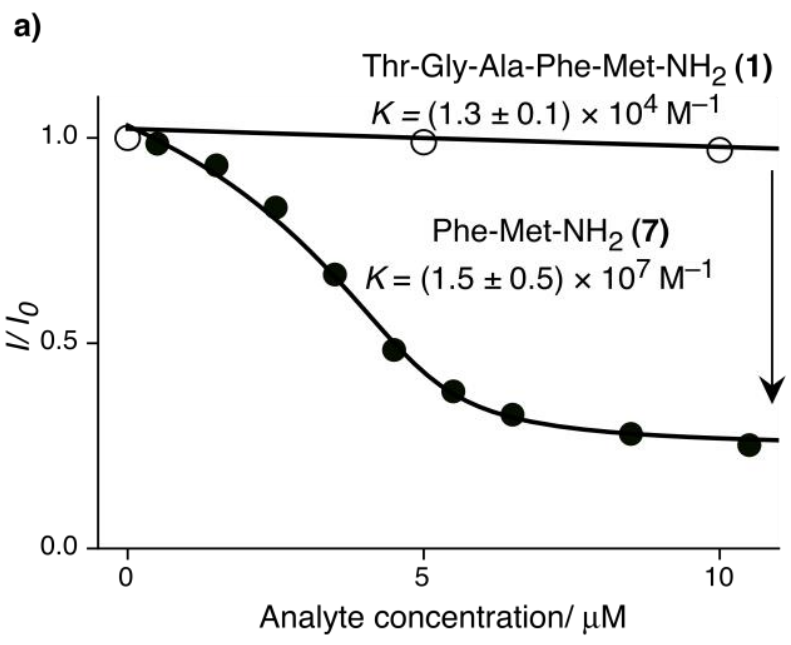

b)

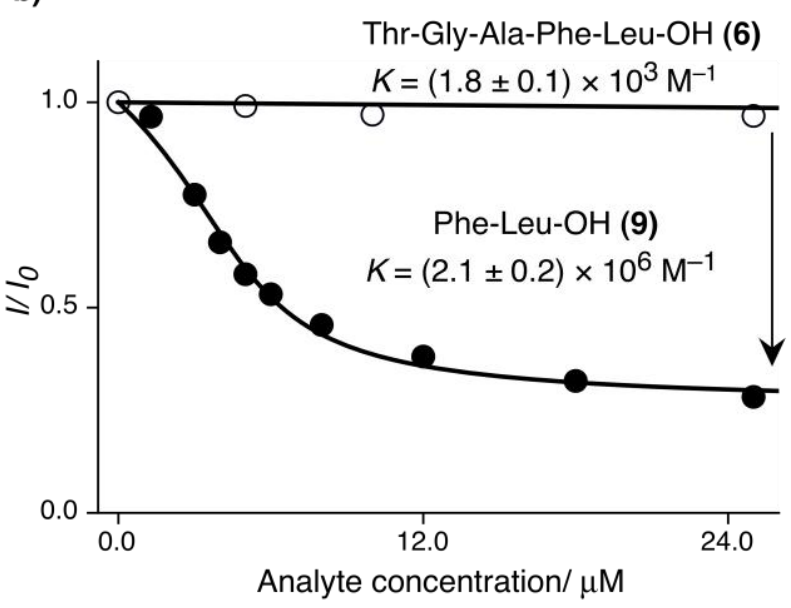

Figure 2. Fluorescence titrations $\left(\lambda_{\mathrm{exc}}=485 \mathrm{~nm}, \lambda_{\mathrm{obs}}=510 \mathrm{~nm}\right)$ of substrates 1 and $\mathbf{6}$ and their proteolysis products (dipeptides 7 and 9) by using competitive displacement of AO (0.5 $\mu \mathrm{M})$ from $\mathrm{CB} 7(5 \mu \mathrm{M})$ in $10 \mathrm{mM}$ ammonium phosphate buffer at $\mathrm{pH} 7.2,37{ }^{\circ} \mathrm{C}$. The titrations for the substrates are cut-off for clarity, see Supporting Information for more data. $I_{0}$ and $I$ are the fluorescence intensities in the absence and presence of competitor, respectively.

When compared to highly selective antibodies, the molecular recognition of peptides by CB7 must be considered as rather unspecific. The synthetic macrocyclic host binds to all pentapeptides 1-6 with very similar affinity, and even the binding constant of the amino acid Phe (10) falls in the same range (Table 1). CB7 shows also little selectivity towards the dipeptides 7-9. However, it differentiates the dipeptides 7-9 reliably from the pentapeptides 1-6, and this substrate/product differentiation is sufficient to set-up robust enzyme assays. When thermolysin is added to the peptide solution containing an enkephalin-based substrate 
and the CB7/AO reporter pair (Scheme 2), the enzymatic product, containing an N-terminal phenylalanine residue, should rapidly (relative to the enzymatic transformation itself) and competitively displace the $\mathrm{AO}$ dye from the $\mathrm{CB} 7$ cavity, thus yielding a decrease in fluorescence intensity that reports the protease activity continuously and in real time. The immediate response is due to the fast rates for the formation and dissociation of the supramolecular assemblies, which, as previously discussed, constitutes an advantage of using macrocycles instead of antibodies. ${ }^{24}$ As can be further seen from the actual titration plots (Figure 2), even working at relatively low substrate concentrations of 5-20 $\mu \mathrm{M}$ should produce a readily detectable change in fluorescence response upon conversion of a substrate to a product. This working concentration range is exactly desirable in protease assays, including those employed in high-throughput screening for pharmaceutical investigations. ${ }^{14-17}$

Table 1: Binding constants $(K)$ of peptides 1-9, phenylalanine 10, and phosphoramidon 11 with $\mathrm{CB} 7$ and proteolytic constants $\left(k_{\mathrm{cat}} / K_{\mathrm{M}}\right)$ for their reaction with thermolysin.

\begin{tabular}{llcl}
\hline Entry & \multicolumn{1}{c}{ Peptide sequence } & $K /\left(10^{4} \mathrm{M}^{-1}\right)^{\mathrm{a}}$ & $k_{\text {cat }} / K_{\mathrm{M}}\left(10^{-4} \mathrm{~s}^{-1} \mathrm{M}^{-1}\right)^{\mathrm{b}}$ \\
\hline $\mathbf{1}$ & Thr-Gly-Ala-Phe-Met-NH & 1.3 & 14 \\
$\mathbf{2}$ & Thr-Gly-DAla-Phe-Met-NH & $\leq 0.005^{\mathrm{c}}$ \\
$\mathbf{3}$ & Thr-Gly-Ala-Phe-Leu-NH 2 & 2.6 & $3.2[7.0]^{\mathrm{d}}$ \\
$\mathbf{4}$ & Thr-Gly-Ser-Phe-Met-NH 2 & 1.9 & 6.9 \\
$\mathbf{5}$ & Thr-Gly-Gly-Phe-Met-NH 2 & 1.4 & 1.2 \\
$\mathbf{6}$ & Thr-Gly-Ala-Phe-Leu-OH & 0.18 & 2.3 \\
$\mathbf{7}$ & Phe-Met-NH 2 & $1500 \pm 500$ & $\mathrm{e}$ \\
$\mathbf{8}$ & Phe-Leu-NH & $\mathrm{e}$ \\
$\mathbf{9}$ & Phe-Leu-OH & $2700 \pm 1500$ & $\mathrm{e}$ \\
$\mathbf{1 0}$ & Phe-OH & 210 & $\mathrm{e}$ \\
$\mathbf{1 1}$ & Phosphoramidon & $2.0[2.5]^{\mathrm{f}}$ & $\mathrm{g}$ \\
\hline
\end{tabular}

${ }^{a}$ Determined by competitive fluorescence titrations, $c f$. Figure 2 and Supporting Information; $15 \%$ error unless explicitly stated. ${ }^{\mathrm{b}}$ Determined by supramolecular tandem assay at varying peptide concentrations (5-55 $\mu \mathrm{M}, n=5-6), c f$. Figure 3; kinetic parameters were determined by nonlinear regression (see Supporting Information); $20 \%$ estimated error. ${ }^{\mathrm{c}}$ Insignificant hydrolysis due to the presence of DAla. ${ }^{\mathrm{d}}$ Value in square brackets refers to exopeptidase 
activity, see text and Supporting Information. ${ }^{\mathrm{e}}$ No conversion detected due to Phe $\mathrm{N}$ terminus.

${ }^{\mathrm{f}}$ In $0.1 \mathrm{M} \mathrm{NaCl}$ solution. ${ }^{56 \mathrm{~g}}$ Phosphoramidon was employed as inhibitor, $c f$. Figure 5. 
Scheme 2. Product-selective fluorescence switch-off tandem assay using CB7 and AO as reporter pair ${ }^{\mathrm{a}}$

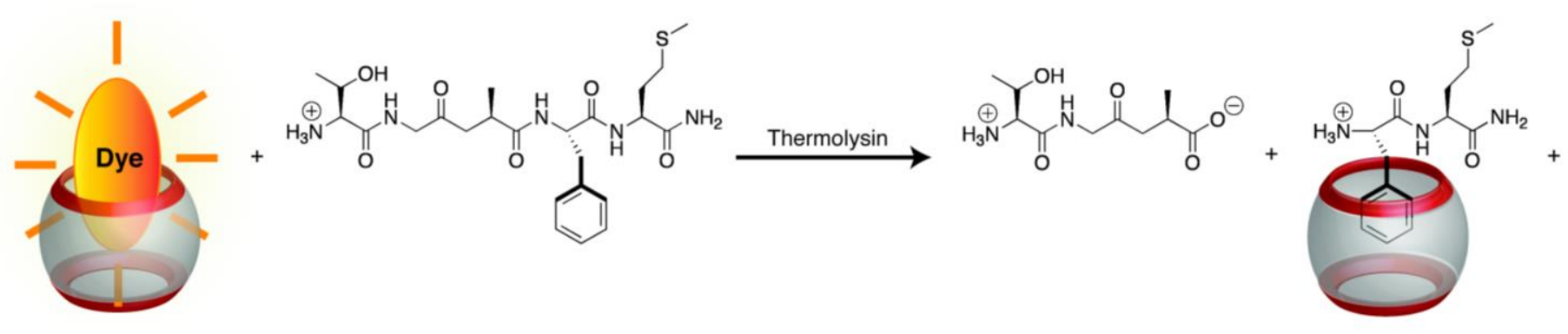

a It should be noted that the dye, substrate, and product are in rapid dynamic competitive equilibrium for encapsulation within the CB7 macrocycle. 
Enzyme Assays. To establish proof of principle for the use of a supramolecular tandem assay to monitor protease activity on unlabelled peptides, we first investigated a series of enkephalinbased peptides (Figure 1) with the sequence Thr-Gly-Ala-Phe-Met-NH2 (1), Thr-Gly-DAla-PheLeu-NH $\mathrm{N}_{2}$ (2), Thr-Gly-Ala-Phe-Leu- $\mathrm{NH}_{2}$ (3), as well as the dipeptide product from proteolysis of enkephalin 1, Phe-Met- $\mathrm{NH}_{2}$ (7).

a)

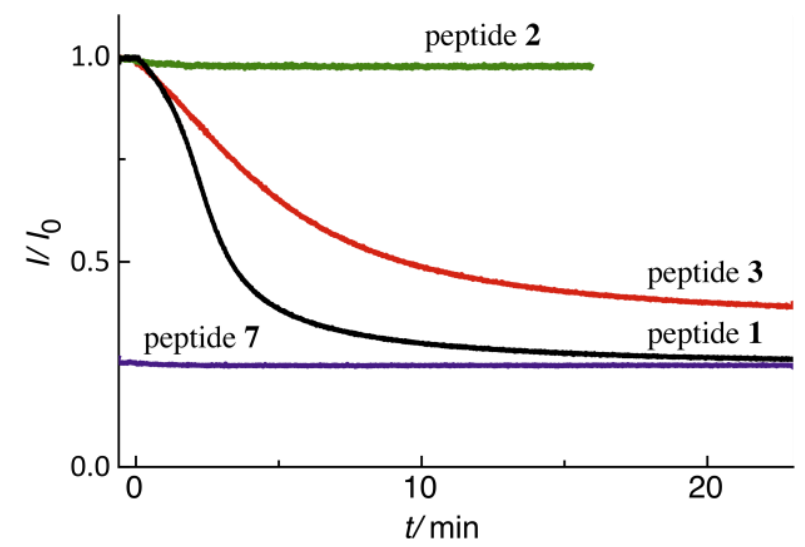

b)

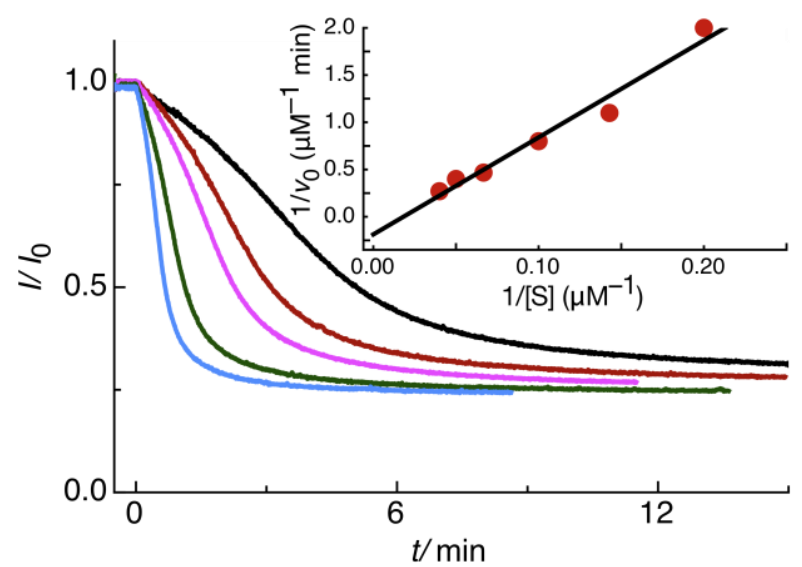

Figure 3: (a) Continuous fluorescence assays $\left(\lambda_{\mathrm{exc}}=485 \mathrm{~nm}, \lambda_{\mathrm{obs}}=510 \mathrm{~nm}\right)$ with the CB7/AO reporter pair $(8 \mu \mathrm{M} / 0.5 \mu \mathrm{M})$ upon addition of thermolysin $(t=0 \mathrm{~min}, 15 \mathrm{nM})$ to peptides 1-3 and $7(30 \mu \mathrm{M})$, at $37{ }^{\circ} \mathrm{C}$. (b) Determination of enzyme kinetic parameters by monitoring of thermolysin $(15 \mathrm{nM})$ activity with varying concentration of enkephalin $1(5-25 \mu \mathrm{M})$ in $10 \mathrm{mM}$ ammonium phosphate buffer, $\mathrm{pH} 7.2$, at $37{ }^{\circ} \mathrm{C}$ with the $\mathrm{CB} 7 / \mathrm{AO}$ reporter pair $(2.5 \mu \mathrm{M} / 0.5 \mu \mathrm{M})$. $I_{0}$ and $I$ are the fluorescence intensities at $t=0$ and $t$, respectively. 
As depicted in Figure 3a, peptides $\mathbf{1}$ and $\mathbf{3}$ were hydrolyzed rapidly, but peptide $\mathbf{2}$ showed insignificant hydrolysis. The stark contrast in the rate of cleavage at the Ala-Phe bond for peptides 1 and $\mathbf{2}$ was due to the substitution of LAla by its enantiomer. The tandem assay thus reflects the previously established substrate selectivity of thermolysin, including the remarkable stereospecificity of the $\mathrm{P}_{1}$ position. ${ }^{48,57-60}$ As can be also seen from Figure 3a, the dipeptide 7 shows no fluorescence response. This signifies that the peptide bond between Phe and Met in this peptide is not cleaved by thermolysin (exopeptidase activity, see below). If it were cleaved, an increase in fluorescence would have been observed, because the product (free Phe, 10) would again constitute a weak competitor (see binding constants in Table 1). Again, it was known that substrates lacking a peptide bond N-terminal to Phe (such as 7) are not digested by thermolysin, ${ }^{53}$ such that our result established a negative control experiment.

Substrate Selectivity. Given the high sensitivity of the tandem assay observed in the initial experiments, we decided to measure the kinetic behavior of thermolysin for substrates with varying amino acids at the $\mathrm{P}_{1}$ position. With peptides $\mathbf{1}$ and $\mathbf{3}$ as parent compounds, the $\mathrm{P}_{1}$ mutations of Ala to Ser (peptide 4) and Ala to Gly (peptide 5) examined the effects of adding a hydroxyl group to the $\beta$ carbon, or removing the $\beta$ carbon, respectively. Peptide 6 is an analogue of 3 with a carboxylate at the $\mathrm{C}$ terminus, which was designed to test the effect of $\mathrm{C}$-terminal charge.

The enzyme-kinetic analysis required the determination of initial rates of reaction. For this purpose, the observed fluorescence decay needed to be related to changes in absolute concentration. ${ }^{25}$ This relationship was achieved by recording the fluorescence response obtained by addition of a known quantity of an authentic sample of reaction product (see Supporting Information). Analysis of the initial reaction rates at varying substrate concentrations (Figure $3 b$ ) yielded the characteristic proteolytic constants $\left(k_{\text {cat }} / K_{\mathrm{M}}\right)$ for the different peptide sequences (inset of Figure $3 \mathrm{~b}$ and Table 1). ${ }^{61}$

Note that our tandem assays allow kinetic measurements for unlabeled peptides, while previous assays were carried out with peptides carrying fluorescent labels such as 2naphthylamide $(2 \mathrm{NA})^{62}$ or dansyl. ${ }^{63}$ The structural differences prevent a direct comparison of the 
absolute proteolytic constants. Nevertheless, peptides $\mathbf{1}\left(k_{\mathrm{cat}} / K_{\mathrm{M}}=14 \times 10^{4} \mathrm{M}^{-1} \mathrm{~s}^{-1}\right)$ and $\mathbf{5}(1.5 \times$ $10^{4} \mathrm{M}^{-1} \mathrm{~s}^{-1}$ ) showed the same order of magnitude as well as the same trends of substrate selectivity as the labeled derivatives Glt-Gly-Ala-Phe-2NA $\left(5.2 \times 10^{4} \mathrm{M}^{-1} \mathrm{~s}^{-1}\right)$ and Glt-Gly-GlyPhe-2NA $\left(0.15 \times 10^{4} \mathrm{M}^{-1} \mathrm{~s}^{-1}\right),{ }^{62}$ which was gratifying to observe.

The data in Table 1 show that the identity of the amino acid residue at the $\mathrm{P}_{1}$ position significantly affects the proteolytic coefficients of thermolysin activity. The values are moderately reduced for the peptides containing glycine and serine at $\mathrm{P}_{1}$ compared to their parent compound 1 with alanine at $\mathrm{P} 1$ position. The binding of the substrate at $\mathrm{P}_{1}$ is governed by hydrophobic interactions, which accounts for the fact that at $\mathrm{P}_{1}$, Gly and Ser are cleaved more slowly than Ala. ${ }^{62,64,65}$ The use of a carboxyl group leads to a slight reduction in enzymatic activity, as indicated by the $k_{\mathrm{cat}} / K_{\mathrm{M}}$ value, presumably due to the known sensitivity of thermolysin towards adjacent charges (see following section, note that most model substrates were amidated at the $\mathrm{C}$ terminus for the convenience of peptide synthesis).

Exo- and Endopeptidase Behavior. During the determination of the $k_{\text {cat }} / K_{\mathrm{M}}$ values for the peptides described above, we stumbled on the unexpected exopeptidase behavior of thermolysin that was specific to the substrate Thr-Gly-Ala-Phe-Leu- $\mathrm{NH}_{2}$ (3). The expected endopeptidase products of the cleavage of substrates Thr-Gly-Ala-Phe-Met-NH2 (1) and Thr-Gly-Ala-Phe-Leu$\mathrm{NH}_{2}$ (3) are Phe-Met- $\mathrm{NH}_{2}(7)$ and Phe-Leu- $\mathrm{NH}_{2}(8)$, respectively. These products bind tightly to CB7 and are therefore responsible for the change in fluorescence intensity during the tandem assay. Therefore, the final steady-state fluorescence response (i.e., after quantitative enzymatic digestion of substrates 1 and 3) was expected to be similar to the fluorescence response brought about by the same concentrations of their endopeptidase products $\mathbf{7}$ and $\mathbf{8}$. This similarity was observed for substrate $\mathbf{1}$ but not for substrate $\mathbf{3}$.

In detail, the enzymatic hydrolysis of $5 \mu \mathrm{M}$ of the substrate Thr-Gly-Ala-Phe-Met- $\mathrm{NH}_{2}$ (1) resulted in complete displacement of the dye from $\mathrm{CB} 7$, as observed by the similarity of the steady-state fluorescence response after complete enzymatic conversion and the response of the same concentration of Phe-Met-NH $\mathrm{NH}_{2}$ (Figures $4 \mathrm{a}$ and $4 \mathrm{c}$ ). In the case of the substrate Thr-GlyAla-Phe-Leu- $\mathrm{NH}_{2}$ (3), however, the final steady-state fluorescence response upon enzymatic 
hydrolysis of $5 \mu \mathrm{M}$ substrate was less than that of its endopeptidase product Phe-Leu-NH2 (8) at the same concentration (see Figure $4 b \& 4 d$ ). In fact, even a concentration of $10 \mu \mathrm{M}$ of substrate 3 was insufficient to produce the same fluorescence response as that produced by $5 \mu \mathrm{M}$ of $\mathbf{8}$. We concluded that the expected product was not quantitatively formed. To account for this result, and inspired by previous experimental observations, ${ }^{48,66,67}$ we suspected the possibility of exopeptidase activity, i.e., enzymatic cleavage of the Phe-Leu peptide bond. We were exactly able to corroborate this unusual pathway for peptide $\mathbf{3}$ by mass spectrometry (see Supporting Information).

The observed exopeptidase cleavage leads to the formation of Thr-Gly-Ala-Phe-OH as (another) product, one that is not further converted by thermolysin. Therefore, the yield of the expected endopeptidase product (8), and the corresponding change in fluorescence response upon the displacement of AO by $\mathbf{8}$, fall below expectation. In fact, the incomplete conversion, signaled by the plateau being reached at higher fluorescence intensities, can be used to assess the ratio of exo- versus endopeptidase cleavage (2.2:1), which, with the endopeptidase kinetics being directly accessible (Figure 4 and Supporting Information), allows the projection of both rates. This analysis affords a $k_{\text {cat }} / K_{\mathrm{M}}$ value of $3.2 \times 10^{4} \mathrm{M}^{-1} \mathrm{~s}^{-1}$ for the endopeptidase activity and a value of $7.0 \times 10^{4} \mathrm{M}^{-1} \mathrm{~s}^{-1}$ for the exopeptidase activity. The higher proteolytic constant for the hydrolysis of the Phe-Leu exo bond (i.e., Leu at P1' position) compared to the hydrolysis of the Ala-Phe endo bond (i.e., Phe at P1') is consistent with the enzyme's preference for hydrophobic P1' residues, whereby increasing the hydrophobic residue from Leu to Phe increases the interaction of the substrate with the active site of the enzyme, whilst decreasing the catalytic efficiency, ${ }^{60,68,69}$ thereby accounting for the observed lower $k_{\text {cat }} / K_{\mathrm{M}}$ value for the endo cleavage. 
a)

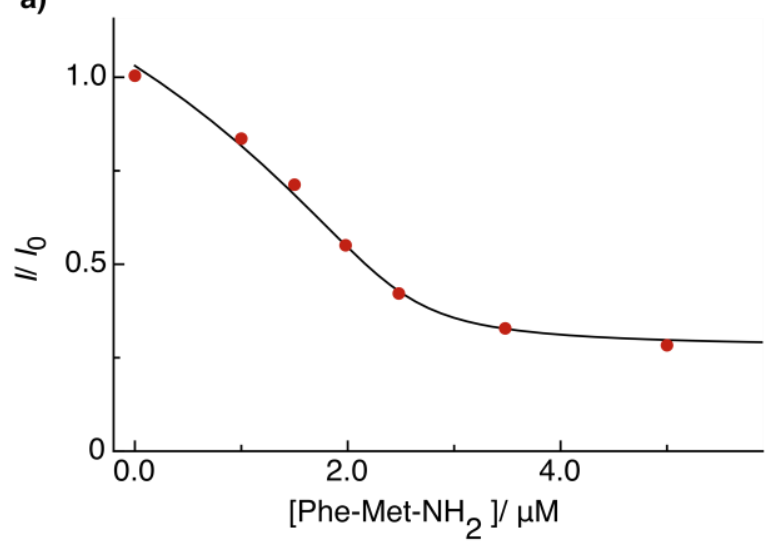

c)

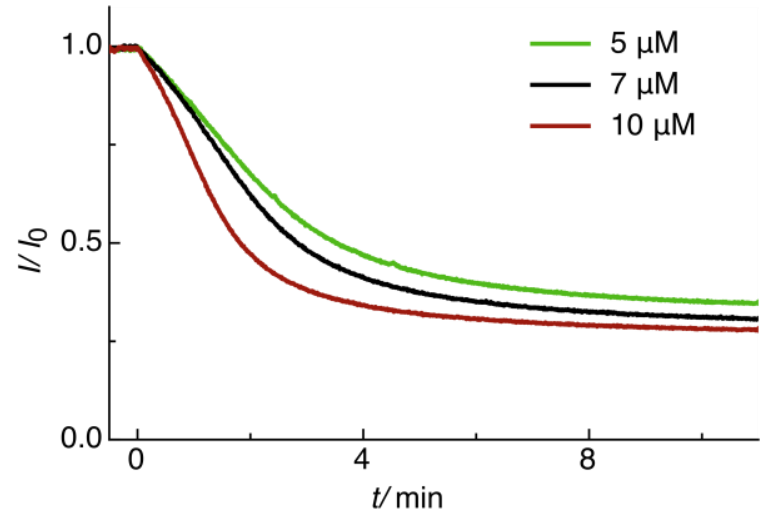

b)

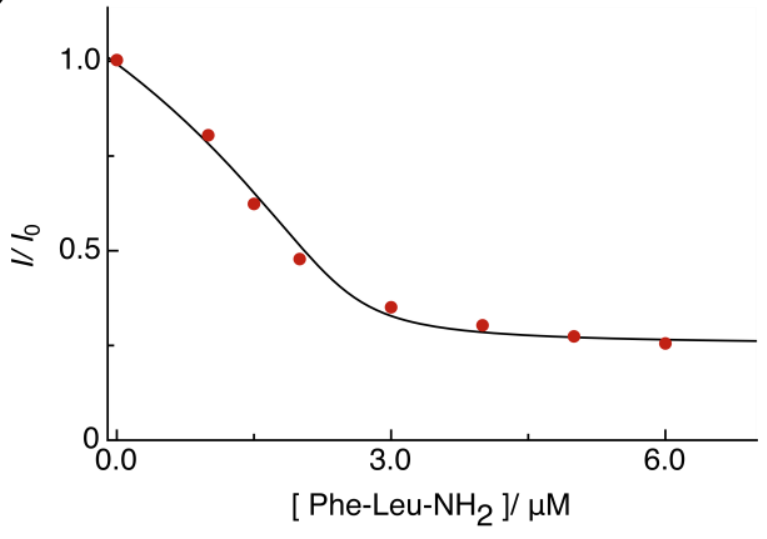

d)

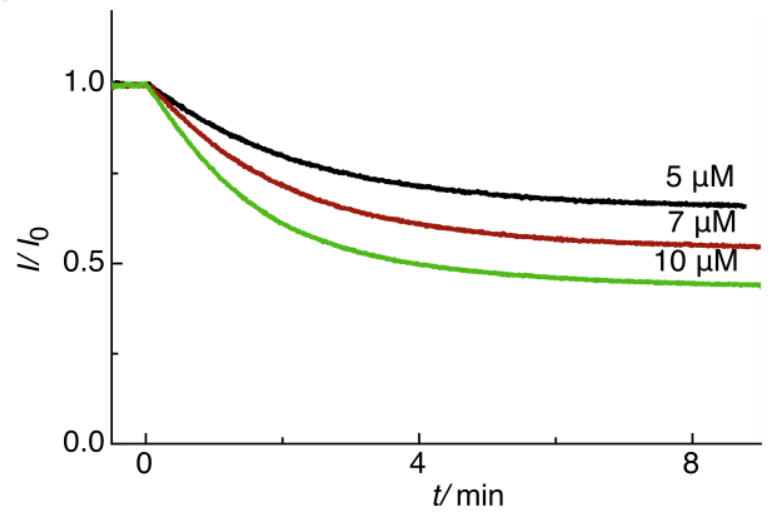

Figure 4: Fluorescence measurements using CB7/AO $\left(2.5 \mu \mathrm{M} \mathrm{CB} 7\right.$ and $0.5 \mu \mathrm{M}$ AO, $\lambda_{\mathrm{exc}}=485$ $\mathrm{nm}, \lambda_{\mathrm{obs}}=510 \mathrm{~nm}$ ) as a reporter pair in $10 \mathrm{mM}$ ammonium phosphate buffer, $\mathrm{pH} 7.2$, at $37^{\circ} \mathrm{C}$. Competitive fluorescence titration plots of a) Phe-Met- $\mathrm{NH}_{2}$ (8) and b) Phe-Leu-NH$(9)$. Tandem protease assays for thermolysin (15 nM) with substrates c) Thr-Gly-Ala-Phe-Met- $\mathrm{NH}_{2}$ (1) and d) Thr-Gly-Ala-Phe-Leu-NH 2 (3).

It is interesting that we observed no exopeptidase activity for the non-amidated peptide ThrGly-Ala-Phe-Leu-OH (6), as confirmed by the plateau region of the fluorescence trace as well as by mass spectrometry (see Supporting Information). This result reveals that the C-terminal charge of the peptide directs endo-versus exopeptidase activity, at least for substrates containing bulky hydrophobic residues (Phe and Leu) at the $\mathrm{P}_{1}{ }^{\prime}$ position. Conversely, a comparison of substrate 3 (exopeptidase cleavage observed) with its product $\mathbf{8}$, for which no conversion by themolysin is observed (Figure $3 \mathrm{a}$ and Supporting Information), further exposes that an N- 
terminal charge directly at phenylalanine suppresses the exopeptidase activity of thermolysin. This observed sensitivity of thermolysin toward adjacent charges supports prior claims based on studies performed by alternative assays with labeled substrates. ${ }^{48,66,67}$

As can be seen from these studies, our label-free protease tandem assay provides information not only on the enzymatic activity, kinetics, and substrate selectivity, but also on the chemoselectivity of the proteolytic cleavage, because the plateau region after quantitative conversion is a signature for the identity of the expected product and thus enables direct quantification of the extent of the expected reaction.

Protease Inhibition. Having established the capability of the assay to effectively measure the kinetics of thermolysin activity, we sought to apply the assay to the determination of enzyme inhibition, which is critical to the evaluation of drug candidates. Using Thr-Gly-Ala-Phe-Met$\mathrm{NH}_{2}$ (1) as the model substrate, inhibition studies for thermolysin were carried out using the product-selective tandem assay principle and the inhibitor phosphoramidon (11), a naturally occurring, potent inhibitor of thermolysin. ${ }^{70-73}$ Inhibitors can hypothetically interfere with the assay principle by binding to the macrocycle. ${ }^{24}$ Fortunately, this can be readily tested by competitive titrations, which afforded a low binding constant for $\mathbf{1 1}\left(1200 \mathrm{M}^{-1}\right.$, Table 1). In the concentration range relevant for studies with potent inhibitors (up to $100 \mathrm{nM}$ ), binding of 11 to CB7 $(<0.3 \%)$ can therefore be safely neglected.

As is typical for competitive inhibitors, we observed that increasing the concentration of 11 decreases the rate of thermolysin hydrolysis via dynamic competition with the substrate for binding to the enzyme, and yet allows the irreversible peptidase reaction on the enzyme•substrate complex to proceed to completion, as observed by similar steady-state fluorescence intensities at all concentrations of inhibitor (Figure 5). The change in initial rates of decrease in fluorescence intensity was used to calculate a $K_{\mathrm{i}}$ value of $(17.8 \pm 0.4) \mathrm{nM},{ }^{74}$ which falls right into the reported range $(3.5-60 \mathrm{nM})$, all determined under slightly varying experimental conditions and with different assay methods employing fluorescently labeled substrates. ${ }^{70,71,75}$ 

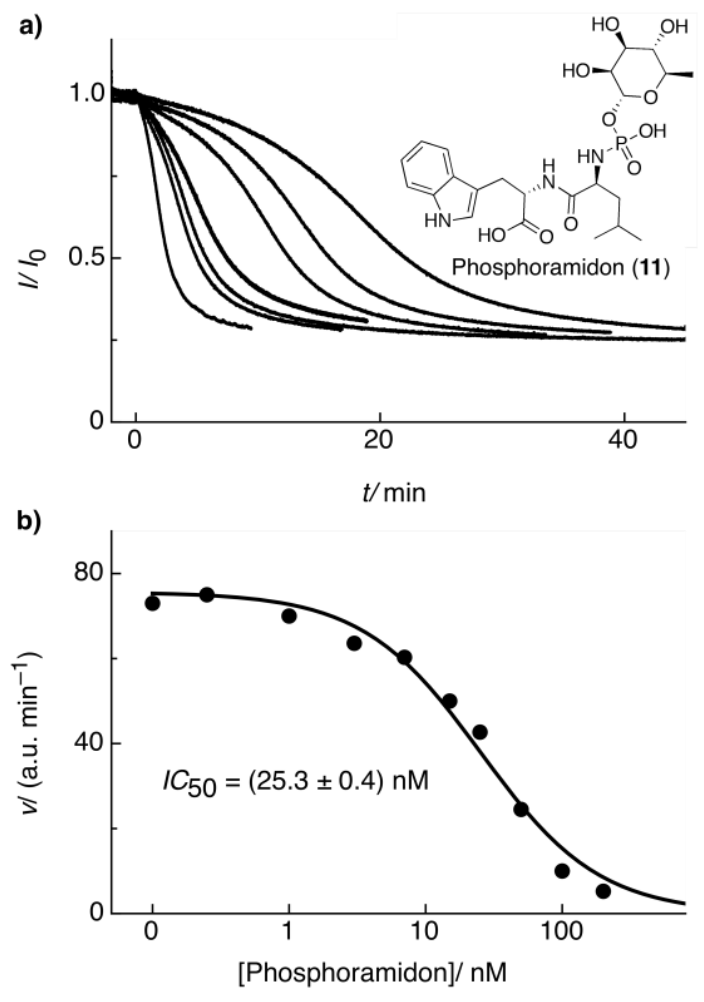

Figure 5: Determination of thermolysin $(15 \mathrm{nM})$ inhibition by phosphoramidon $(\mathbf{1 1}, 0-100 \mathrm{nM})$ in the presence of $10 \mu \mathrm{M}$ Thr-Gly-Ala-Phe-Met-NH 2 (1) by using the CB7/AO $(0.5 \mu \mathrm{M} / 2.5 \mu \mathrm{M})$ reporter pair in $10 \mathrm{mM}$ ammonium phosphate, $\mathrm{pH} 7.2$, at $37^{\circ} \mathrm{C}$. a) Continuous fluorescence traces $\left(\lambda_{\mathrm{exc}}=485 \mathrm{~nm}, \lambda_{\mathrm{obs}}=510 \mathrm{~nm}\right)$ upon addition of $10 \mu \mathrm{M}$ Thr-Gly-Ala-Phe-Met- $\mathrm{NH}_{2}(\mathbf{1})$ for the determination of the initial rates. b) Corresponding dose-response curve for inhibition of thermolysin by phosphoramidon (11).

\section{Conclusions}

The addition of macrocyclic host molecules in combination with fluorescent dyes establishes a label-free method for the real-time, continuous monitoring of protease activity by fluorescence spectroscopy. Protease assays using unmodified substrates are important because they enable the detailed characterization of the natural substrate selectivity of a target protease as well as its activity in the presence of inhibitors. We have successfully applied the tandem assay principle to the continuous monitoring of the hydrolysis of enkephalin-based peptides by thermolysin. In doing so, we have established proof-of-principle for the use of cucurbituril-based fluorescent reporter pairs for proteases. The general selectivity of macrocycles (even if moderate in 
comparison to specific receptors) renders potentially broad transferability of this assay to other exo- and endo-peptidases. Furthermore, for the first time, we have extended the applicability of tandem assays towards an in-depth profiling of enzyme activity for a wide range of substrates, towards sensing enzyme substrate stereospecificity, and have demonstrated the potential of this assay for the screening of inhibitors. These applications of tandem assays to monitor proteolytic activity have significant implications for drug design as well as medical diagnostics, where proteases are important disease markers.

\section{Experimental Section}

Materials. Peptides 1-8 were synthesized by standard Fmoc solid-phase synthesis protocols on Rink amide MBHA resin (for C-terminal amides) or Wang acid resin (for peptide $\mathbf{6}$ containing a C-terminal carboxylic acid) and purified by reversed phase HPLC. Purity was verified by reversed phase analytical HPLC and ${ }^{1} \mathrm{H}$ NMR spectroscopy. Identity was verified by electrospray mass spectrometry.

Peptide Phe-Leu-OH (9) and amino acid Phe-OH (10) were used as received from Bachem and Applichem respectively. Cucurbit[7]uril (CB7) was synthesized according to the literature. ${ }^{76-}$ ${ }^{78}$ Acridine orange (AO), thermolysin (lyophilized powder, $36.5 \mathrm{U} / \mathrm{mg}$ ) and phosphoramidon were used as received from Sigma-Aldrich.

Methods. Absorbance measurements were performed with a Varian Cary 4000 spectrophotometer. The concentrations of peptides 1-10 were determined assuming the extinction coefficient of free phenylalanine at $257 \mathrm{~nm}, \varepsilon_{257}=195 \mathrm{M}^{-1} \mathrm{~cm}^{-1} \cdot{ }^{79}$ For thermolysin and phosphoramidon, $\varepsilon_{280}=61100 \mathrm{M}^{-1} \mathrm{~cm}^{-1}$ and $\varepsilon_{280}=5500 \mathrm{M}^{-1} \mathrm{~cm}^{-1}$, respectively, were used. ${ }^{63,71} \mathrm{~A}$ Varian Eclipse spectrofluorimeter was used for steady-state fluorescence measurements and for the enzyme assays.

Continuous assays were performed with $0-55 \mu \mathrm{M}$ peptide, $2.5 \mu \mathrm{M}$ CB7 and $0.5 \mu \mathrm{M} \mathrm{AO}\left(\lambda_{\text {exc }}\right.$ $=485 \mathrm{~nm}, \lambda_{\mathrm{obs}}=510 \mathrm{~nm}$ ) in $10 \mathrm{mM}$ ammonium buffer, $\mathrm{pH} 7.2$, in a variable-temperature cell holder at $37.0 \pm 0.1{ }^{\circ} \mathrm{C}$, and the reaction was initiated by addition of thermolysin $(15 \mathrm{nM})$. For the inhibition studies, the mixture of thermolysin $(10 \mathrm{nM})$ and phosphoramidon $(0-100 \mathrm{nM})$ was 
pre-incubated for 15 minutes at $37.0 \pm 0.1{ }^{\circ} \mathrm{C}$ in the presence of the reporter pair and the reaction was initiated by addition of $10 \mu \mathrm{M}$ Thr-Gly-Ala-Phe-Met- $\mathrm{NH}_{2}$ (1).

Acknowledgements. Financial support from the Deutsche Forschungsgemeinschaft (DFG grant NA-686/5-1, GG and WMN), Fonds der Chemischen Industrie (WMN), National Science Foundation (CHE-0748483, VR and ARU), and Welch Foundation (W-1640, ARU) is gratefully acknowledged. GG thanks Prof. Dr. Nikolai Kuhnert and Ms. Anja Müller for help with the mass-spectrometric measurements. ARU thanks Anita Chaudhari for preliminary contributions.

Supporting Information. Fluorescence titration plots of peptide substrates, details on the calculations of the enzymatic reaction rates, mass spectra, and supporting evidence for the exopeptidase activity are available in the Supporting Information file. This information is available free of charge via the Internet at http://pubs.acs.org.

\section{References}

* To whom correspondence should be addressed.

$\S$ Jacobs University Bremen

$\dagger$ Trinity University

(1) Carmeliet, P. Nat. Med. 2003, 9, 653-660.

(2) Koblinski, J. E.; Ahram, M.; Sloane, B. F. Clin. Chim. Acta 2000, 291, 113-135.

(3) Patel, T.; Gores, G. J.; Kaufmann, S. H. FASEB J. 1996, 10, 587-597.

(4) Puente, X. S.; Sanchez, L. M.; Overall, C. M.; Lopez-Otin, C. Nat. Rev. Genet. 2003, 4, 544-558.

(5) Turk, B. Nat. Rev. Drug Discovery 2006, 5, 785-799.

(6) Egeblad, M.; Werb, Z. Nat. Rev. Cancer 2002, 2, 161-174.

(7) Krane, S. M. Arthritis Res. Ther. 2003, 5, 2-4.

(8) Esler, W. P.; Wolfe, M. S. Science 2001, 293, 1449-1454.

(9) Adekoya, O. A.; Sylte, I. Chem. Biol. Drug Des. 2009, 73, 7-16.

(10) Goddard, J. P.; Reymond, J. L. Curr. Opin. Biotechnol. 2004, 15, 314-322.

(11) Goddard, J. P.; Reymond, J. L. Trends Biotechnol. 2004, 22, 363-370.

(12) Reymond, J. L.; Fluxa, V. S.; Maillard, N. Chem. Commun. 2009, 34-46.

(13) Sittampalam, G. S.; Kahl, S. D.; Janzen, W. P. Curr. Opin. Chem. Biol. 1997, 1, 384-391.

(14) Hennig, A.; Roth, D.; Enderle, T.; Nau, W. M. ChemBioChem 2006, 7, 733-737.

(15) Hennig, A.; Florea, M.; Roth, D.; Enderle, T.; Nau, W. M. Anal. Biochem. 2007, $360,255-265$.

(16) Marguerre, A. K.; Kramer, R. Bioorg. Med. Chem. Lett. 2009, 19, 5757-5759.

(17) Yongzheng, Y.; Reymond, J. L. Mol. BioSyst. 2005, 1, 57-63. 
(18) Su, J.; Rajapaksha, T. W.; Peter, M. E.; Mrksich, M. Anal. Chem. 2006, 78, 49454951.

(19) Macrae, M. X.; Blake, S.; Jiang, X. Y.; Capone, R.; Estes, D. J.; Mayer, M.; Yang, J. ACS Nano 2009, 3, 3567-3580.

11969.

(20) Sorde, N.; Das, G.; Matile, S. Proc. Natl. Acad. Sci. U. S. A. 2003, 100, $11964-$

(21) Pogson, M.; Georgiou, G.; Iverson, B. L. Curr. Opin. Biotechnol. 2009, 20, 390-

397.

(22) Hennig, A.; Bakirci, H.; Nau, W. M. Nat. Methods 2007, 4, 629-632.

(23) Bailey, D. M.; Hennig, A.; Uzunova, V. D.; Nau, W. M. Chem.-Eur. J. 2008, 14, 6069-6077.

(24) Nau, W. M.; Ghale, G.; Hennig, A.; Bakirci, H.; Bailey, D. M. J. Am. Chem. Soc. 2009, 131, 11558-11570.

(25) Florea, M.; Nau, W. M. Org. Biomol. Chem. 2010, 8, 1033-1039.

(26) Niikura, K.; Bisson, A. P.; Anslyn, E. V. J. Chem. Soc., Perkin Trans. 2 1999, 1111-1114.

(27) Nguyen, B. T.; Wiskur, S. L.; Anslyn, E. V. Org. Lett. 2004, 6, 2499-2501.

(28) Zhang, T. Z.; Anslyn, E. V. Org. Lett. 2007, 9, 1627-1629.

(29) Kemp, S.; Wheate, N. J.; Wang, S.; Collins, J. G.; Ralph, S. F.; Day, A. I.;

Higgins, V. J.; Aldrich-Wright, J. R. J. Biol. Inorg. Chem. 2007, 12, 969-979.

(30) Saleh, N.; Koner, A. L.; Nau, W. M. Angew. Chem., Int. Ed. 2008, 47, 5398-5401.

(31) Kim, C.; Agasti, S. S.; Zhu, Z.; Isaacs, L.; Rotello, V. M. Nature Chem. 2010, 2, 962-966.

(32) Wyman, I. W.; Macartney, D. H. Org. Biomol. Chem. 2010, 8, 247-252.

(33) Koner, A. L.; Ghosh, I.; Saleh, N.; Nau, W. M. Can. J. Chem. 2011, 89, 139-147.

(34) Ghosh, S.; Isaacs, L. J. Am. Chem. Soc. 2010, 132, 4445-4454.

(35) Hennig, A.; Ghale, G.; Nau, W. M. Chem. Commun. 2007, 1614-1616.

(36) Lee, D.-W.; Park, K. M.; Banerjee, M.; Ha, S. H.; Lee, T.; Suh, K.; Paul, S.; Jung, H.; Kim, J.; Selvapalam, N.; Ryu, S. H.; Kim, K. Nature Chem. 2011, 3, 154-159.

(37) Lagona, J.; Mukhopadhyay, P.; Chakrabarti, S.; Isaacs, L. Angew. Chem., Int. Ed. 2005, 44, 4844-4870.

(38) Buschmann, H. J.; Cleve, E.; Schollmeyer, E. Inorg. Chim. Acta 1992, 193, 93 -

97.

(39) Buschmann, H. J.; Cleve, E.; Jansen, K.; Wego, A.; Schollmeyer, E. J. Inclusion Phenom. Macrocyclic Chem. 2001, 40, 117-120.

(40) Isaacs, L. Chem. Commun. 2009, 619-629.

(41) Jeon, W. S.; Moon, K.; Park, S. H.; Chun, H.; Ko, Y. H.; Lee, J. Y.; Lee, E. S.; Samal, S.; Selvapalam, N.; Rekharsky, M. V.; Sindelar, V.; Sobransingh, D.; Inoue, Y.; Kaifer, A. E.; Kim, K. J. Am. Chem. Soc. 2005, 127, 12984-12989.

(42) Marquez, C.; Hudgins, R. R.; Nau, W. M. J. Am. Chem. Soc. 2004, 126, 5806-

5816. 14517.

(43) Bush, M. E.; Bouley, N. D.; Urbach, A. R. J. Am. Chem. Soc. 2005, 127, 14511-

(44) Heitmann, L. M.; Taylor, A. B.; Hart, P. J.; Urbach, A. R. J. Am. Chem. Soc. 2006, 128, 12574-12581. 
(45) Rekharsky, M. V.; Yamamura, H.; Ko, Y. H.; Selvapalam, N.; Kim, K.; Inoue, Y. Chem. Commun. 2008, 2236-2238.

(46) Nguyen, H. D.; Dang, D. T.; van Dongen, J. L. J.; Brunsveld, L. Angew. Chem., Int. Ed. 2010, 49, 895-898.

(47) Chinai, J. M.; Taylor, A. B.; Ryno, L. M.; Hargreaves, N. D.; Morris, C. A.; Hart, P. J.; Urbach, A. R. J. Am. Chem. Soc. 2011, in press.

(48) Matsubara, H. Biochem. Biophys. Res. Commun. 1966, 24, 427-430.

(49) Shrimpton, C. N.; Smith, A. I.; Lew, R. A. Endocr. Rev. 2002, 23, 647-664.

(50) Turner, A. J.; Isaac, R. E.; Coates, D. BioEssays 2001, 23, 261-269.

(51) Meilandt, W. J.; Yu, G. Q.; Chin, J.; Roberson, E. D.; Palop, J. J.; Wu, T.; Scearce-Levie, K.; Mucke, L. J. Neurosci. 2008, 28, 5007-5017.

(52) Antonczak, S.; Monard, G.; Lopez, M. R.; Rivail, J. L. J. Mol. Model. 2000, 6, $527-538$.

(53) Malfroy, B.; Schwartz, J. C. Biochem. Biophys. Res. Commun. 1985, 130, 372-

378.

(54) Rush, R. S.; Mitas, M.; Powers, J. C.; Tanaka, T.; Hersh, L. B. Arch. Biochem. Biophys. 1984, 231, 390-399.

(55) Shaikh, M.; Mohanty, J.; Singh, P. K.; Nau, W. M.; Pal, H. Photochem. Photobiol. Sci. 2008, 7, 408-414.

(56) Rekharsky, M. V.; Yamamura, H.; Inoue, C.; Kawai, M.; Osaka, I.; Arakawa, R.; Shiba, K.; Sato, A.; Ko, Y. H.; Selvapalam, N.; Kim, K.; Inoue, Y. J. Am. Chem. Soc. 2006, 128, 14871-14880.

(57) The substrate specificity of proteases is denoted using the Schechter and Berger nomenclature. The amino acids in peptide substrates are labeled as $\mathrm{H}-\mathrm{P}_{\mathrm{X}} \ldots \mathrm{P}_{2}-\mathrm{P}_{1}-\mathrm{P}_{1}$ '- $\mathrm{P}_{2}$ ' $\ldots \mathrm{P}_{\mathrm{X}}$ '$\mathrm{OH}$ where $\mathrm{P}_{1}$ is the position of an amino acid at the $\mathrm{N}$-terminus of the cleavage site and $\mathrm{P}_{1}$ ' is the position of an amino acid at the C-terminus of the cleavage site.

(58) Schechter, I.; Berger, A. Biochem. Biophys. Res. Commun. 1967, 27, 157-162.

(59) Abramowi, N.; Schechter, I.; Berger, A. Biochem. Biophys. Res. Commun. 1967, $29,862-867$.

(60) Morihara, K.; Tsuzuki, H. Eur. J. Biochem. 1970, 15, 374-380.

(61) Under physiological conditions with very low substrate concentration, the $k_{\text {cat }} / K_{\mathrm{M}}$ value provides a direct measure for the catalytic efficacy and is therefore commonly employed to scale the substrate specificity of an enzyme. At $[\mathrm{S}]<<K_{\mathrm{M}}$, most of the active sites are unoccupied, that is, the concentration of free enzyme, [E], is approximately equal to the total concentration of enzyme, $[\mathrm{E}]_{0}$. The Michaelis-Menten equation then simplifies to $v_{0}=k_{\mathrm{cat}} / K_{\mathrm{M}} \times$ $[\mathrm{S}] \times[\mathrm{E}]_{0}$, and $k_{\text {cat }} / K_{\mathrm{M}}$ becomes the apparent bimolecular rate constant for the interaction between the substrate and the enzyme, $c f$. Berg, J. M.; Tymoczko, J. L.; Stryer, L. Biochemistry; 5 ed.; W. H. Freeman and Company.: New York, 2002. Hennig, A.; Florea, M.; Roth, D.; Enderle, T.; Nau, W. M. Anal. Biochem. 2007, 360, 255-265. Koshland, D. E. Bioorg. Chem. 2002, 30, 211-213.

(62) Pozsgay, M.; Michaud, C.; Liebman, M.; Orlowski, M. Biochemistry 1986, 25, 1292-1299.

(63) Yang, J. J.; Vanwart, H. E. Biochemistry 1994, 33, 6508-6515.

(64) Hersh, L. B.; Morihara, K. J. Biol. Chem. 1986, 261, 6433-6437.

(65) Oda, K.; Takahashi, T.; Takada, K.; Tsunemi, M.; Ng, K. K. S.; Hiraga, K.; Harada, S. FEBS Lett. 2005, 579, 5013-5018. 
(66) Ligne, T.; Pauthe, E.; Monti, J. P.; Gacel, G.; Larreta-Garde, V. BBA-Protein Struct. M. 1997, 1337, 143-148.

(67) Pauthe, E.; Dauchez, M.; Berry, H.; Berjot, M.; Monti, J.-P.; Alix, A. J. P.; Larreta-Garde, V. R. Ann. N. Y. Acad. Sci. 1998, 864, 458-462.

(68) de Kreij, A.; van den Burg, B.; Veltman, O. R.; Vriend, G.; Venema, G.; Eijsink, V. G. H. Eur. J. Biochem. 2001, 268, 4985-4991.

(69) Inouye, K.; Yasukawa, K. BBA-Proteins Proteom. 2007, 1774, 1281-1288.

(70) Inouye, K.; Kuzuya, K.; Tonomura, B. J. Biochem. 1994, 116, 530-535.

(71) Kitagishi, K.; Hiromi, K. J. Biochem. 1984, 95, 529-534.

(72) Komiyama, T.; Suda, H.; Aoyagi, T.; Takeuchi, T.; Umezawa, H. Arch. Biochem. Biophys. 1975, 171, 727-731.

(73) Tronrud, D. E.; Monzingo, A. F.; Matthews, B. W. Eur. J. Biochem. 1986, 157, 261-268.

(74) The equation $\left.K_{\mathrm{i}}=\left(I C_{50}-0.5 \times[\mathrm{E}]_{0}\right) /\left(1+\left([\mathrm{S}] / K_{\mathrm{M}}\right)\right)\right]$ was used for conditions of tight stoichiometric competitive inhibition for a monosubstrate reaction, with $I C_{50}$ determined from the dose-response curve in Figure $5 \mathrm{~b}$ and $[\mathrm{S}] / K_{\mathrm{M}} \approx 0$, due to $[\mathrm{S}]<<K_{\mathrm{M}}\left(K_{\mathrm{M}}=108 \mathrm{mM}\right.$ for peptide 1), cf. Copeland, R. A.; Lombardo, D.; Giannaras, J.; Decicco, C. P. Bioorg. Med. Chem. Lett. 1995, 5, 1947-1952.

(75) MarieClaire, C.; Ruffet, E.; Antonczak, S.; Beaumont, A.; ODonohue, M.; Roques, B. P.; FournieZaluski, M. C. Biochemistry 1997, 36, 13938-13945.

8100 .

(76) Day, A.; Arnold, A. P.; Blanch, R. J.; Snushall, B. J. Org. Chem. 2001, 66, 8094-

(77) Kim, J.; Jung, I. S.; Kim, S. Y.; Lee, E.; Kang, J. K.; Sakamoto, S.; Yamaguchi, K.; Kim, K. J. Am. Chem. Soc. 2000, 122, 540-541.

(78) Marquez, C.; Huang, F.; Nau, W. M. IEEE Trans. Nanobsci. 2004, 3, 39-45.

(79) Fasman, G. D. In Handbook of Biochemistry and Molecular Biology, Proteins; 3rd ed.; Fasman, G. D., Ed.; CRC Press: 1976, p 183-203. 


\section{TOC Graphic}

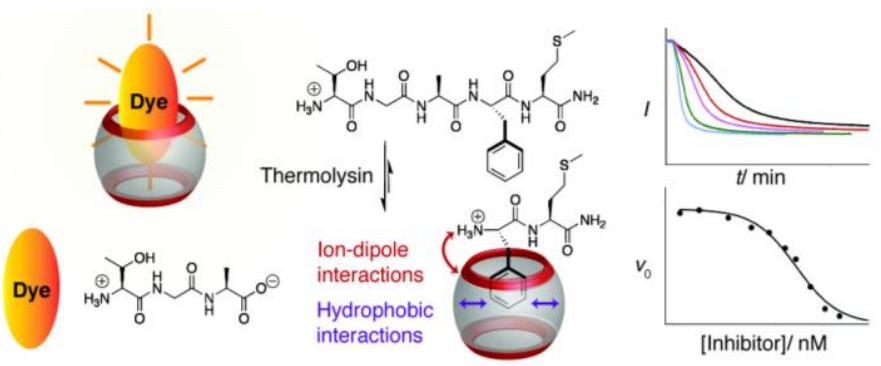

